\title{
PSO based Direct Power Control for a Multifunctional Grid Connected Photovoltaic System
}

\author{
M.R. Bengourina ${ }^{1}$, M. Rahli ${ }^{2}$, S. Slami ${ }^{3}$, L. Hassaine ${ }^{4}$ \\ ${ }^{1,2}$ Laboratoir LORE, Faculty of Electrical Engineering, University of Science and Technology Oran, Algeria \\ ${ }^{3}$ Sciences and Technology Faculty University of Djelfa, Algeria \\ ${ }^{4}$ Centre de Développement des Energies Renouvelables (CDER), Algeria
}

\begin{tabular}{l} 
Article Info \\
\hline Article history: \\
Received May 28, 2017 \\
Revised Jan 14, 2018 \\
Accepted Jan 28, 2018 \\
\hline
\end{tabular}

\section{Keyword:}

Direct ontrol of Power Particle Swarm Optimization Photovoltaic system PI controller Shunt Actif Power Filter

\section{Corresponding Author:}

Mohamed Rida Bengourina, Laboratoir LORE, Faculty of Electrical Engineering, University of Science and Technology Oran (USTO), Algeria BP 1505, Oran El M'naouer, Algeria Email: bengourina.rida@yahoo.fr, rida.bengourina@univ-usto.dz

\begin{abstract}
This paper presents a grid-connected photovoltaic system (PV) used as a shunt active power filter (SAPF) to provide the power factor correction, harmonic elimination, reactive power compensation and to simultaneously supply power from a PV system to the utility. A direct power control (DPC) method is used for controlling the system to feed the photovoltaic energy in synchronization with grid and provide power quality improvement. The PI parameters of DC-link voltage controller are tuned using the Particle Swarm Optimization (PSO) algorithm without the need for an exact mathematical model of system. This PI-PSO controller gives better results for robustness, harmonic minimization and reduces the overshoot and undershoots of PI controller. The overall control of system is tested in Matlab/Simulink environment. Then, the simulations results demonstrate the robustness and feasibility of proposed method.
\end{abstract}

Copyright () 2018 Institute of Advanced Engineering and Science. All rights reserved.

\section{INTRODUCTION}

The solar energy is the most popular source among the alternative energy resource without emission of pollutants energy conversion is done [1]. In an effort to use the solar energy effectively, a great deal of research has been done on the grid-connected photovoltaic generation systems. In PV systems connected to the grid, the inverter that converts the output direct current (DC) of the solar modules to the alternate current (AC) is receiving increased interest in order to generate power to utility [2].

Today, the widespread use of nonlinear loads in power systems causes circulation of harmonics and reactive currents in the distribution lines [3] [4]. If the grid-connected PV system is applied to nonlinear loads, the power quality is relatively poorer. To avoid these problems, the grid-connected PV system should not only supply active power to the system via MPPT, but also improve the power quality (low THD and unity power factor) [5].

By modifying the control of the inverter, active filtering feature can also be included in the PV interfacing inverter and thus saves the cost of additional active filter. Various control types of shunt active filter were presented in the literature [6]. In this article, we propose the direct power control (DPC). The DPC strategy is based on the instantaneous active and reactive power comparators. The active power command is provided from a dc-bus voltage controller block, while the reactive power command is directly given from the outside of the controller. Errors between the commands and the estimated feedback power are input to the hysteresis comparators [7] [8].

In the DPC technique, the active power is delivered from the outer proportional- integral (PI) 
controller. This PI controller is formulated as an optimization problem[9]. In this work, we propose the use of the particle swarm optimization (PSO) method to search for the optimal parameters of a PI controller. DPC based on classical PI regulator and PSO algorithm is developed and a comparison study is presented. To show the performances, a numerical simulation is performed.

\section{SYSTEMS CONFIGURATIONS}

The structure of the grid-connected PV system is shown in Figure. 1. It consists of a photovoltaic array connected through a dc-dc boost converter to a three-phase inverter that is connected to a grid through a simple filter and nonlinear load.

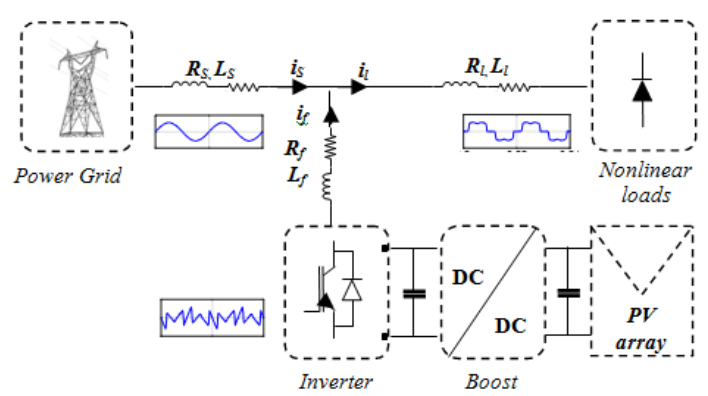

Figure 1. Grid-Connected Inverter Interfaced with PV System

\subsection{PV Array Model}

The PV module is the unity of base for the construction of a PV array. We have used the PV module model of a single diode. This model is the most commonly used due to good results [10]. The current-voltage relationship is given by:

$$
\begin{aligned}
& I_{P V}=I_{p h}-I_{d}-I_{s h} \\
& I_{P V}=I_{p h}-I_{s} \cdot\left[\exp \left\{q \cdot \frac{\left(V_{P V}+R_{s} \cdot I_{P V}\right)}{A k T}\right\}-1\right]+\frac{V_{P V}-R_{s} \cdot I_{P V}}{R_{s h}}
\end{aligned}
$$

Where:

Iph: the current generated by the incident light; Is: the reverse saturation or leakage current of the diode; Rs: the equivalent series resistance; Rsh: the equivalent parallel resistance; q: the electron charge $(1.60217646 \times$ 10-19 C); k: the Boltzmann constant (1.3806503 × 10-23 J/K); A: Quality Factor of diode.

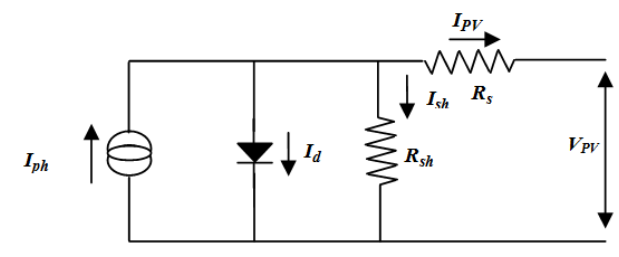

Figure 2. Equivalent Circuit of a PV Cell 


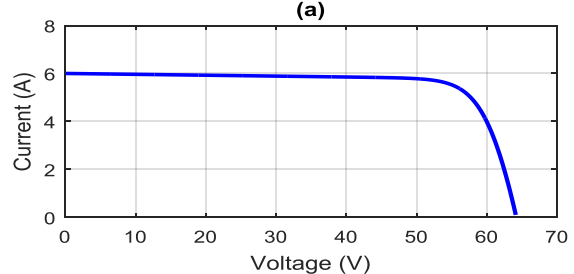

(a)

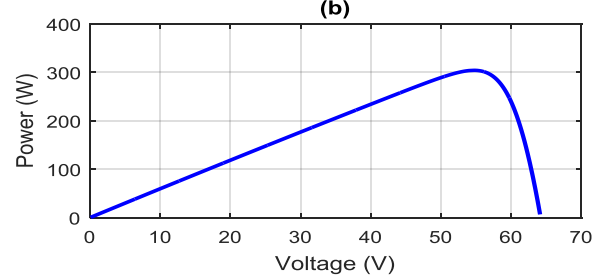

(b)

Figure 3. (a) I-V Characteristics, (b) P-V Characteristics

The PV model is simulated using the Sun Power SPR-305E-WHT-D PV panel. The simulated I-V and P-V characteristics of the SPR-305E-WHT-D PV module at standard climatic conditions are shown in Figure. 3. (a) and (b), respectively.

\subsection{Boost Converter Modeling}

Figure.4 shows the equivalent circuit of the DC-DC boost converter. These converters can be described using ordinary differentiation equations as follows:

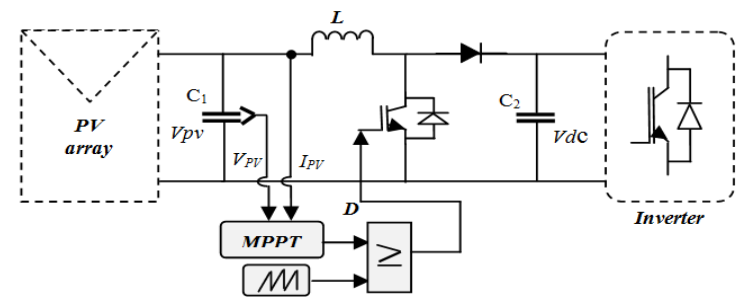

Figure 4. Control Scheme of DC-DC Boost Converter

$$
\begin{gathered}
I_{\text {Lboost }}=I_{p v}-C_{1} \frac{d V_{p v}}{d t} \\
I_{d c}=(1-D) I_{\text {Lboost }}-C_{2} \frac{d V_{d c}}{d t} \\
V_{p v}=(1-D) V_{d c}-L \frac{d I_{\text {Lboost }}}{d t}
\end{gathered}
$$

D: is the duty cycle.

The switch is on for a period equal to DT, and the switch is off for an interval time equal to (1 - D) T.

\subsection{Maximum Power Point Tracking}

Several publications on MPP methods are regularly published in the literature. For our study, we chose the MPPT algorithm of P\&O. P\&O method is one of the popular methods to track the maximum-power point and probably the most frequently used in practice, mainly due to its easy implementation. [11][12]. The working principle of $\mathrm{P} \& \mathrm{O}$ is depicted by the flow chart in Figure. 5. 


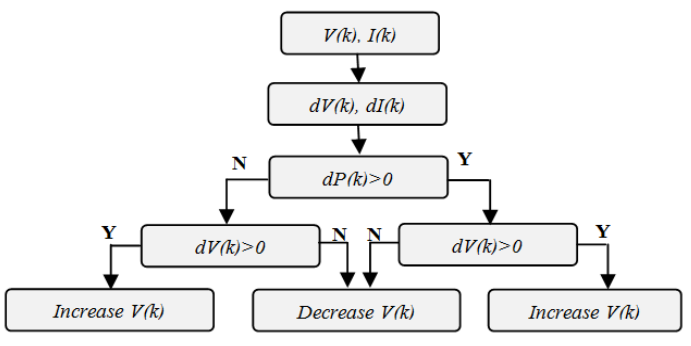

Figure 5. Flowchart of the P\&O Algorithm

\subsection{Active Power Filter}

The structure of the active filter consists essentially of two parts, a power and a control part. The power part consists of an inverter, a coupling filter and a source of energy. The control part is used to control the switching of semiconductor elements forming the inverter from the power part. Au through appropriate control strategies, it is possible to generate harmonic signals at the output of the inverter to offset those present on the power grid, such as. [13]

$$
i_{s}=i_{l}+i_{f}
$$

$i_{s}$ : current of source.; $i_{l}:$ current of the load; $i_{f}:$ current compensation.

\section{DIRECT POWER CONTROL}

The main idea of the direct power control (DPC) originally proposed by Ohnishi (1991) and further developed by Noguchi and Takahachi in 1998, is similar to the direct torque control (DTC) of induction machines. Instead of flux and torque, the active power $(\mathrm{P})$ and reactive power (q) are selected as two instantaneous magnitudes to control [14][7]. The figure .2 shows the configuration of the direct power control without voltage sensor for a three phase inverter.

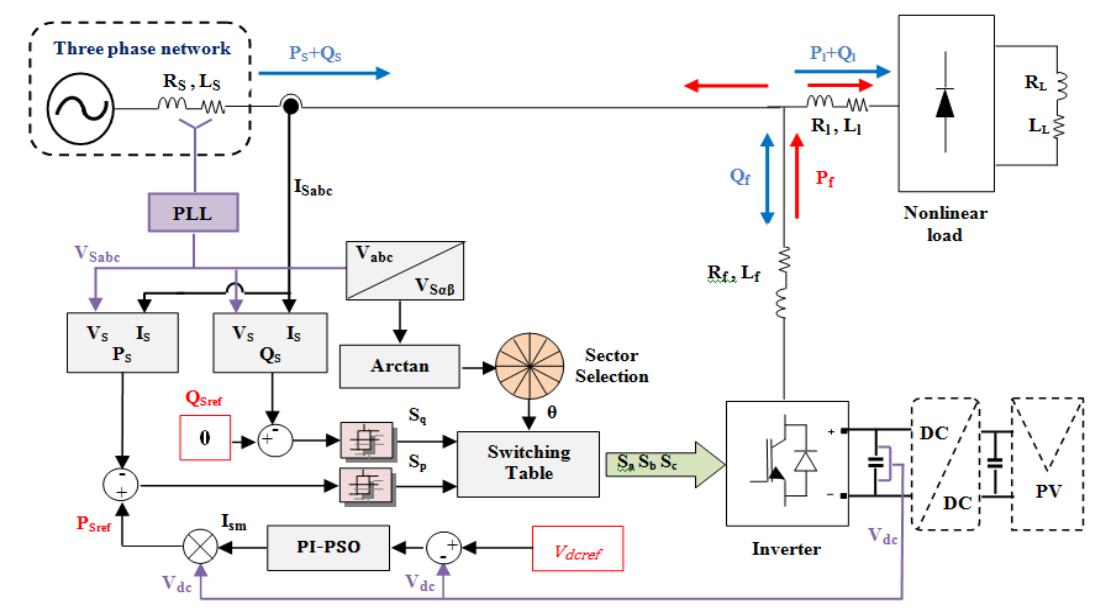

Figure 6. General Structure of Shunt Active Filter Controlled by DPC

The estimated values of $\left(\mathrm{p}_{\mathrm{s}}\right)$ and $\left(\mathrm{q}_{\mathrm{s}}\right)$ in terms of the three phase line currents and voltages can be derived as: [14]

$$
\begin{aligned}
& S_{s}=P_{S}+j Q_{S} \\
& P_{S}=v_{s a} \cdot i_{s a}+v_{s b} \cdot i_{s b}+v_{s c} \cdot i_{s c}
\end{aligned}
$$




$$
Q_{S}=\frac{1}{\sqrt{3}}\left[\left(v_{s b}-v_{s c}\right) \cdot i_{s a}+\left(v_{s c}-v_{s a}\right) \cdot i_{s b}+\left(v_{s a}-v_{s b}\right) \cdot i_{s c}\right]
$$

The phase of the power-source voltage vector is converted to the digitized signal $\theta_{N}$ Error! Reference source not found. For this purpose, the working plane $(\alpha, \beta)$ is divided into 12 sectors in Figure. 7. The sectors can be numerically determined by the following equation. [7].

Or: $N=1,2,3 \ldots .12$ is the number of the sector

$$
\theta=\operatorname{Arctg}\left(\frac{V_{\beta}}{V_{\alpha}}\right)
$$

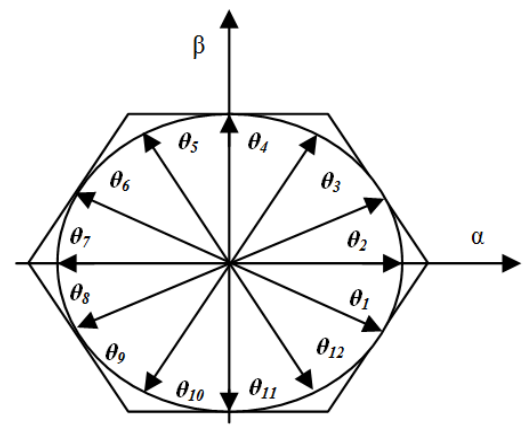

Figure 7. Plant $(\alpha, \beta)$ Divided in 12 Sector

\subsection{Hysteresis control and switching table}

The references of reactive power (qref) and active power (pref) are compared with the estimated reactive $(q s)$ and active ( $p s)$ values. Errors between the commands and the estimated feedback power are input to the hysteresis comparators and digitized to the signals $\mathrm{Sp}$ and $\mathrm{Sq}$. The output signal of the active power controller is defined:

$$
\left\{\begin{array}{l}
p_{\text {ref }}-p_{s}<-h_{p}=>S_{p}=0 \\
p_{\text {ref }}-p_{s}>-h_{p}=>S_{p}=1
\end{array}\right.
$$

And similarly for the reactive power controller as:

$$
\left\{\begin{array}{l}
q_{\text {ref }}-q_{s}<-h_{q}=>S_{q}=0 \\
q_{\text {ref }}-q_{s}>-h_{q}=>S_{q}=1
\end{array}\right.
$$

For all sectors the switching table proposed is represented in the Table 1.

Table 1. All Sectors Switching Table

\begin{tabular}{cccccccccccccc}
\hline $\mathrm{S}_{\mathrm{p}}$ & $\mathrm{S}_{\mathrm{q}}$ & $\theta_{1}$ & $\theta_{2}$ & $\theta_{3}$ & $\theta_{4}$ & $\theta_{5}$ & $\theta_{6}$ & $\theta_{7}$ & $\theta_{8}$ & $\theta_{9}$ & $\theta_{10}$ & $\theta_{11}$ & $\theta_{12}$ \\
\hline 1 & 1 & $V_{6}$ & $V_{7}$ & $V_{1}$ & $V_{0}$ & $V_{2}$ & $V_{7}$ & $V_{3}$ & $V_{0}$ & $V_{4}$ & $V_{7}$ & $V_{5}$ & $V_{0}$ \\
1 & 0 & $V_{7}$ & $V_{7}$ & $V_{0}$ & $V_{0}$ & $V_{7}$ & $V_{7}$ & $V_{0}$ & $V_{0}$ & $V_{5}$ & $V_{7}$ & $V_{0}$ & $V_{0}$ \\
0 & 1 & $V_{6}$ & $V_{1}$ & $V_{1}$ & $V_{2}$ & $V_{2}$ & $V_{3}$ & $V_{3}$ & $V_{4}$ & $V_{4}$ & $V_{5}$ & $V_{5}$ & $V_{6}$ \\
0 & 0 & $V_{1}$ & $V_{2}$ & $V_{2}$ & $V_{3}$ & $V_{3}$ & $V_{4}$ & $V_{4}$ & $V_{3}$ & $V_{3}$ & $V_{6}$ & $V_{6}$ & $V_{l}$ \\
\hline
\end{tabular}

\subsection{PI controller}

The regulation of the continuous voltage of inverter is ensured by a regulator of PI type. The error between the voltage of the capacitor $\mathrm{V}_{\mathrm{dc}}$ and the reference voltage $\mathrm{V}_{\mathrm{dcref}}$ is used as an input to PI Controller 
and the output is the reference active power $\mathrm{p}_{\text {ref. }}$. The transfer function of the PI Controller is:

$$
G(s)=k p+\frac{k i}{s}
$$

Where, $k_{P}$ is the proportional constant gain and $k_{i}$ is the integral constant gain. These gains are tuned by using Particle Swarm Optimization (PSO).

\section{PARTICLE SWARM OPTIMIZATION}

The particle swarm optimization (PSO) algorithm was first described in 1995 by Kennedy and Eberhart [15] [16]. The technique has evolved greatly since then. PSO is a stochastic, population based evolutionary computer algorithm for problem solving. In a PSO system, a swarm of individuals (called particles) fly through the search space. Each particle represents a candidate solution to the optimization problem. The position of a particle is influenced by the best position visited by itself (i.e., its own experience) and the position of the best particle in its neighbourhood (i.e., the experience of neighboring particles). When the neighbourhood of a particle is the entire swarm, the best position in the neighbourhood is referred to as the global best particle, and the resulting algorithm is referred to a global best PSO. When smaller neighbourhoods are used, the algorithm is generally referred to a local best PSO.

The performance of each particle (i.e., how close the particle is from the global optimum) is measured using a fitness function that varies depending on the optimization problem. Each particle in the swarm is represented by the following characteristics [15] [17]:

$x_{i}$ is the current position of the particle; $v_{i}$ is the current velocity of the particle; $y_{i}$ is the personal best position of the particle is the neighbourhood best position of the particle. The personal best position of particle $i$ is the best position visited by particle $i$ so far. Let $F$ denote the objective function. Then the personal best of a particle at time step $t$ is updated as:

$$
y_{i}(t+1)=\left\{\begin{array}{c}
y_{i}(t) \text { if } F\left(x_{i}(t+1) \geq F\left(y_{i}(t)\right)\right. \\
x_{i}(t+1) \text { if } F\left(x_{i}(t+1)<F\left(y_{i}(t)\right)\right.
\end{array}\right.
$$

For the gbest model, the best particle is determined from the entire swarm by selecting the best personal position. If the position of the global best particle is denoted by the vector then:

Where:

$$
y=\min \left\{F\left(y_{0}(\mathrm{t})\right), \ldots \ldots \ldots \ldots, \mathrm{F}\left(y_{s}(t)\right)\right\}
$$

And: $s$ denotes the size of the swarm.

The velocity update step is specified for each dimension

$$
j: \mathbf{j} \in,\left\{1, \ldots \ldots \ldots . . ., \mathrm{N}_{d}\right\}
$$

Hence, $v_{i, j}$ represents the $j$ th element of the velocity vector of the $i t h$ particle. Thus the velocity of particle $i$ is updated using the following equation:

$$
v_{i, j}=\omega \cdot v_{i, j}(t)+c_{1} \cdot \Delta_{1}+c_{2} \cdot \Delta_{2}
$$

Where:

$$
\begin{aligned}
& \Delta_{1}=r_{1, j} \cdot\left(y_{i, j}(t)-x_{i, j}(t)\right) \\
& \Delta_{2}=r_{2, j} \cdot\left(y_{j}^{n}(t)-x_{i, j}(t)\right)
\end{aligned}
$$

$\omega$ is the inertia weight, $c_{1}$ and $c_{2}$ are the acceleration constants, and random coefficients distributed as: $r_{1, j}$ and $r_{2, j} \in\{0.1\}$

The position of particle $i, x_{i}$ is then updated using the following equation: 


$$
x_{i}(t+1)=x_{i}(t)+v_{i}(t+1)
$$

This process is repeated until a specified number of iterations is exceeded, or velocity updates are close to zero. The quality of particles is measured using a fitness function which reflects the optimality of a particular solution. The following steps summarize the basic PSO algorithm:

\subsection{PSO Algorithm}

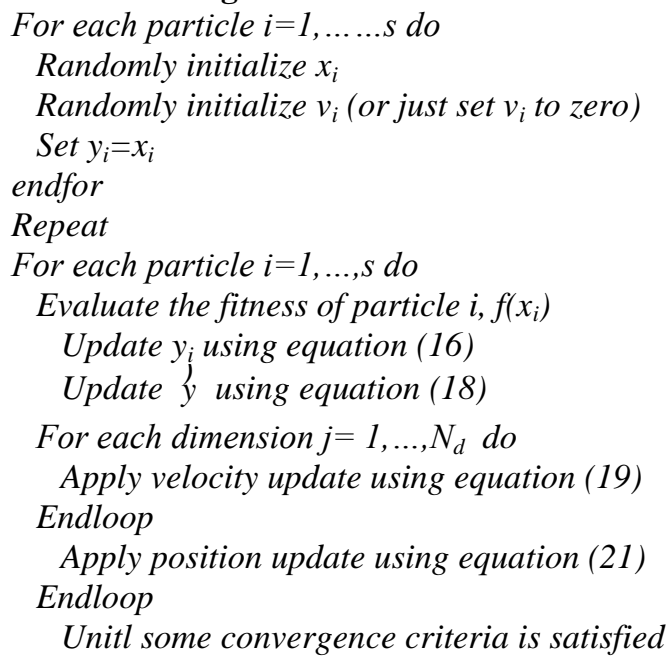

\subsection{Objective function formulation}

In this study, the PSO algorithm is proposed to tune the PI parameters of voltage controller by minimizing the cost function. So that, the proportional $(\mathrm{kp})$ and integral $(\mathrm{ki})$ gains of PI controller is defined as the problem parameters that should be optimized.

Thus, each individual of population is composed of the controller parameters $k p$ and $k i$. Then, the optimization problem of PI controller is formulated as the minimization of the integral time absolute error ITAE and of the maximum overshoot. Therefore, the objective function is defined as:

$$
\begin{gathered}
j=\sum_{t=1}^{n} \int_{0}^{t s} t\left|\Delta e r r_{t}\right| \cdot d t \\
k_{p \text { min }} \leq k_{p} \leq k_{p \text { max }}, \quad k_{\text {imin }} \leq k_{i} \leq k_{\text {imax }}
\end{gathered}
$$

Where:

$n$ : is the total number of points for which the optimization is carried out.

$t s$ : is the time rang of simulation or simulation period.

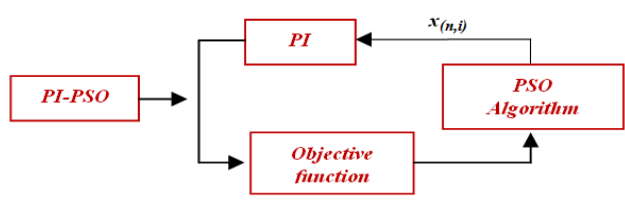

Figure 8. Insertion of PSO Approach with the PI Controller

\section{SIMULATION RESULTS AND ANALYSIS}

The system depicted in Figure. 1 and 6 has been simulated using the SimPowerSystem with Sfunction of Matlab/Simulink installed on a computer system with Intel Core i5-4210 CPU, 1.70 GHz speed and 4GO of memory. Parameters used in simulation are as follows: 
Table 2. Parameters of PSO Algorithm

\begin{tabular}{cc}
\hline Parameter & Values \\
\hline Swarm size & 10 \\
Number of iterations & 100 \\
r1 & 0.3 \\
r2 & 0.95 \\
c1 & 1.45 \\
c2 & 1.45 \\
\hline
\end{tabular}

Table 3. Parameters of DC-DC Boost Converter

\begin{tabular}{cc}
\hline Parameter & Values \\
\hline$f$ switching & $5 \mathrm{kHz}$ \\
Output voltage & $400 \mathrm{~V}$ \\
Inductor L & $10 \mathrm{mH}$ \\
Capacitor C & $100 \mu \mathrm{F}$ \\
\hline
\end{tabular}

Table 4. SAPF Parameters.

\begin{tabular}{cc}
\hline Parameter & Values \\
\hline Source voltage & $125 \mathrm{~V}$ \\
Supply frequency & $50 \mathrm{~Hz}$ \\
Source impedance $\mathrm{R}_{\mathrm{S}}, \mathrm{L}_{\mathrm{S}}$ & $0.1 \Omega, 0.1 \mathrm{mH}$ \\
Filter impedance $\mathrm{R}_{\mathrm{f}}, \mathrm{L}_{\mathrm{f}}$ & $0.1 \Omega, 2.6 \mathrm{mH}$ \\
Line impedance $\mathrm{R}_{\mathrm{l}}, \mathrm{L}_{\mathrm{l}}$ & $0.1 \Omega, 0.5 \mathrm{mH}$ \\
DC-link capatitor $\mathrm{C}$ & $2.2 \mu \mathrm{H}$ \\
Diode rectifier load $\mathrm{R}_{\mathrm{L}}, \mathrm{L}_{\mathrm{L}}$ & $20 \Omega, 2 \mathrm{mH}$
\end{tabular}

The source current and its spectrum before connecting SAPF feed by PV system are illustrated in Figure 9. The results show that the system is affected by the nonlinear load during the operation. Where, the Total Harmonic Distortion (THD) of the supply current is high and equals $27.57 \%$.

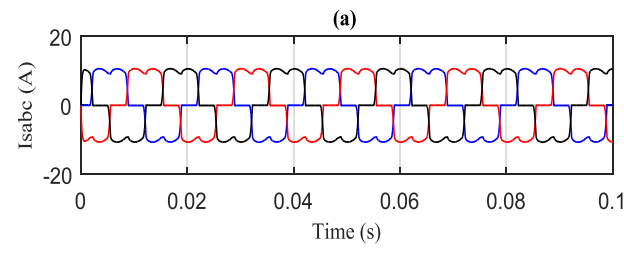

(a)

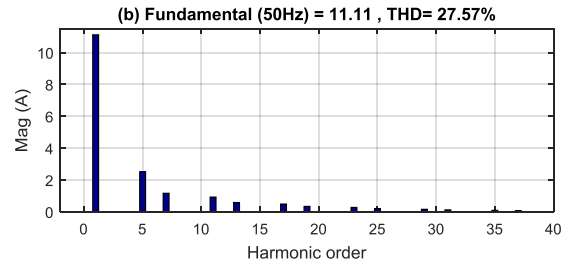

(b)

Figure 9. (a) Supply Current before Harmonics Compensation, (b) Harmonic Spectrum.

To verify the performances and robustness of the proposed control and the research algorithm of maximum power point tracking (MPPT), a variable profile irradiance to sweep all modes of operation of our system is done. Figure 10 shows the solar irradiance level starts from $0 \mathrm{~W} / \mathrm{m}^{2}$, then increases to $600 \mathrm{~W} / \mathrm{m}^{2}$, after that decreases to $200 \mathrm{~W} / \mathrm{m}^{2}$ and finally increases to $1000 \mathrm{~W} / \mathrm{m}^{2}$. 


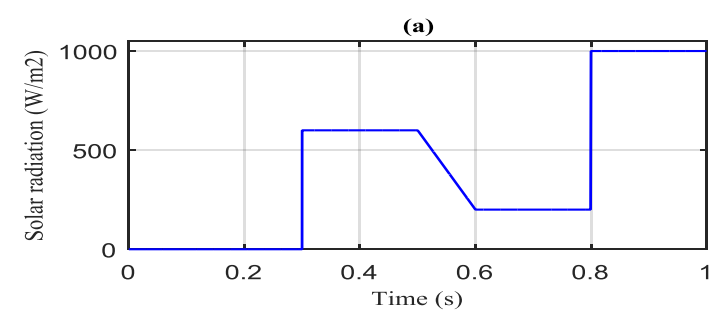

(a)

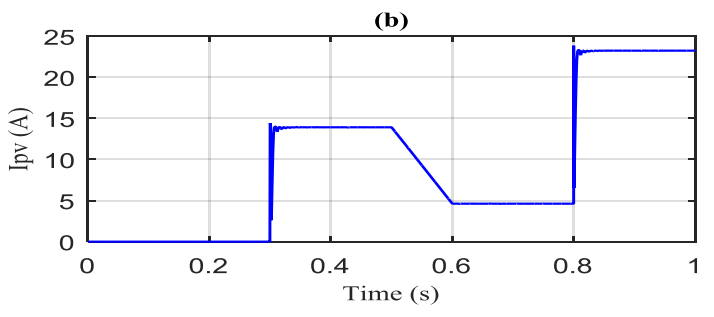

(b)

Figure 10. (a) Solar Radiation. (b) Current PV Array.

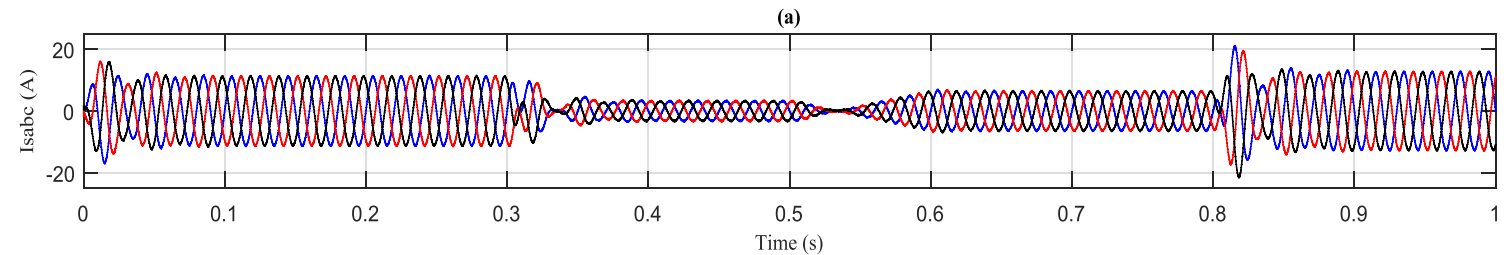

(a)

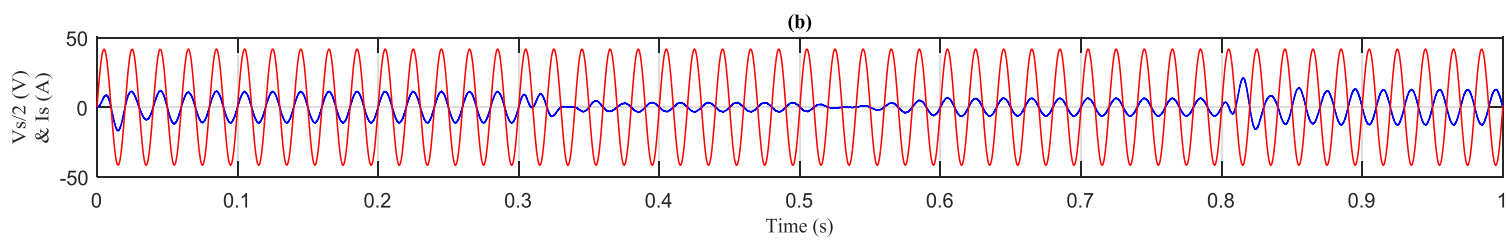

(b)

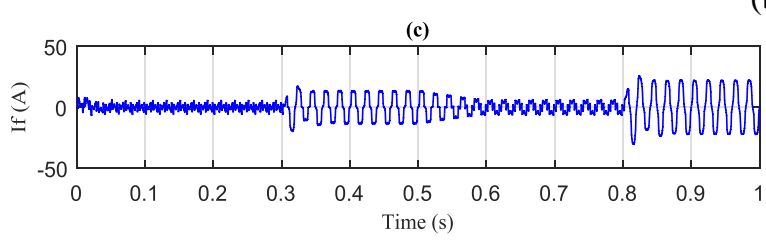

(c)

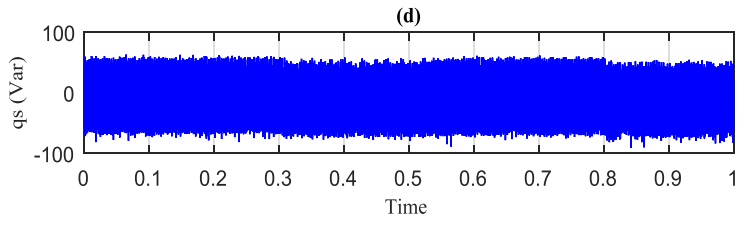

(d)

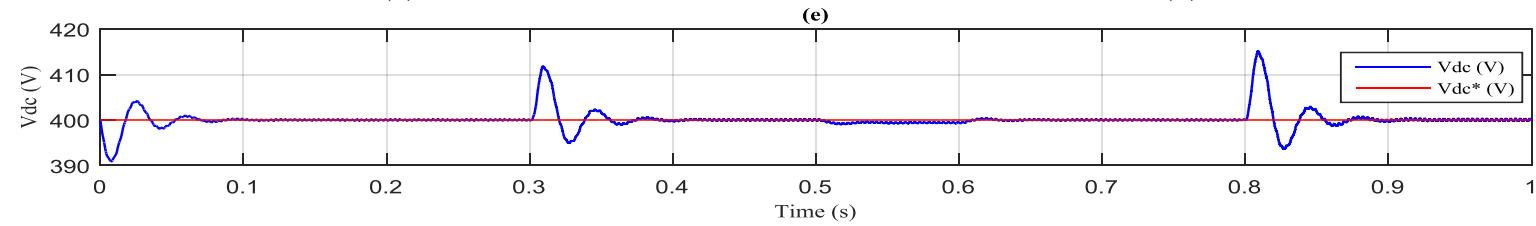

(e)

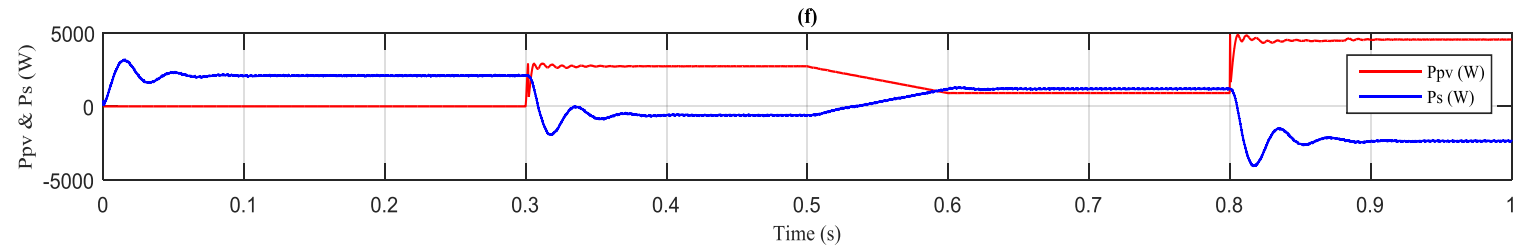

(f)

Figure 11. Simulation Results of the Proposed DPC with PI Controller: (a) Source Current, (b) Source Voltage and Source Current, (c) Filter Current, (d) Reactive Power, (e) DC-Link Voltage vdc, (f) Active Power and PV Power. 


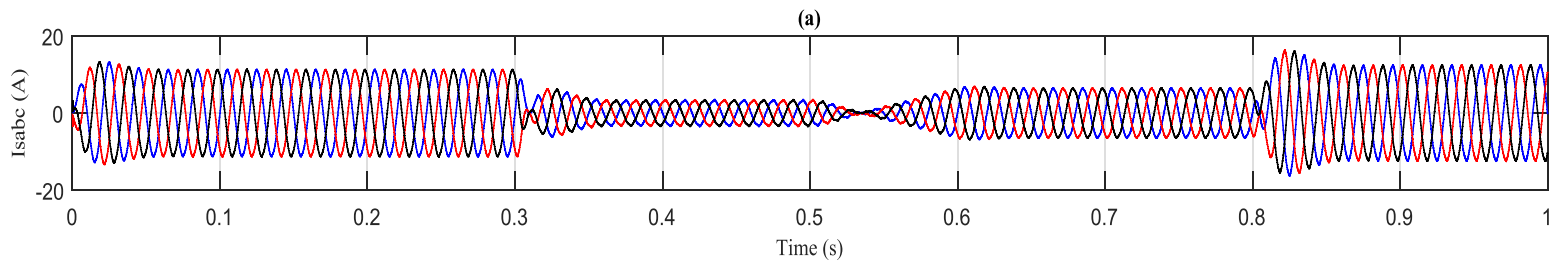

(a)

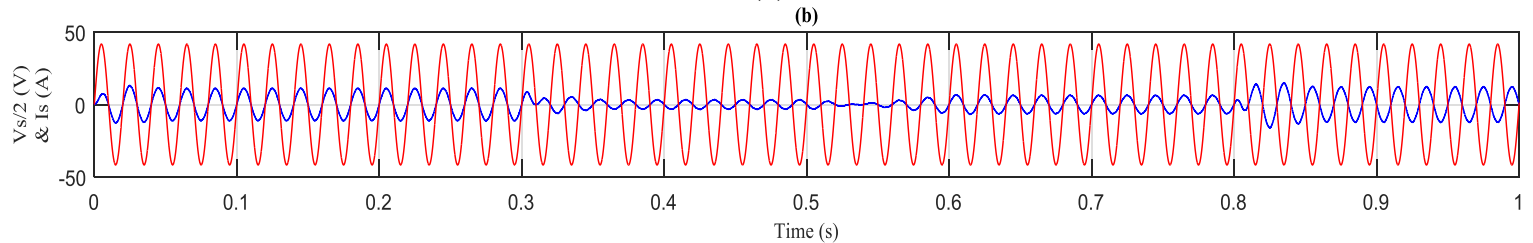

(b)

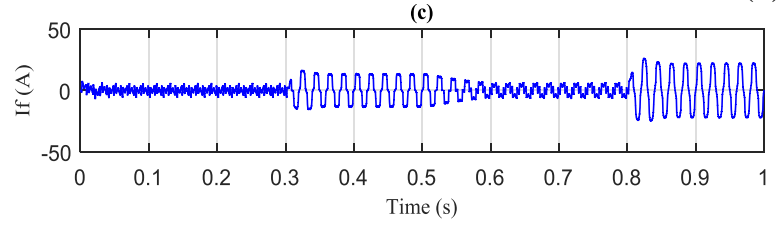

(c)

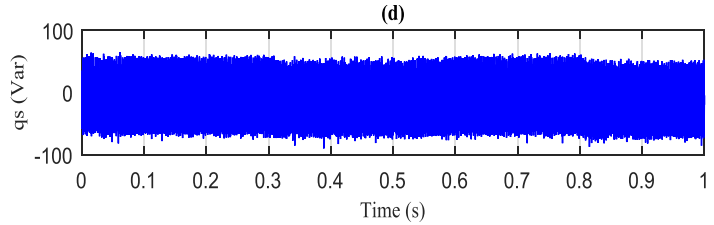

(d)

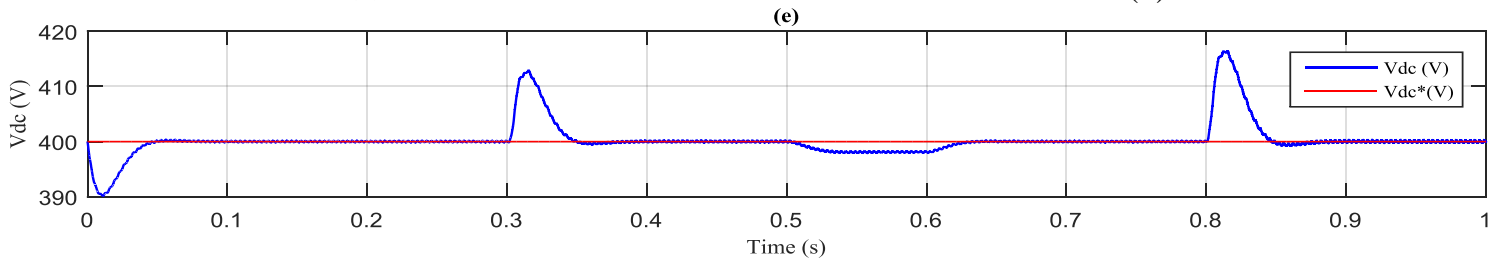

(e)

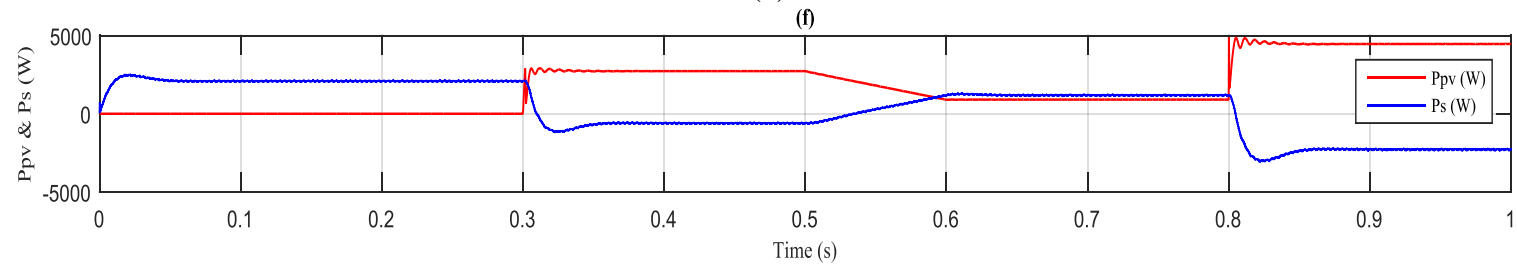

(f)

Figure 12. Simulation Results of the Proposed DPC with PI-PSO Controller: (a) Source Current, (b) Source Voltage and Source Current, (c) Filter Current, (d) Reactive Power, (e) DC-Link Voltage Vdc, (f) Active Power and PV Power.

Figure 11 and 12 shows the system with PI and PI-PSO controllers. The source current (Is), source voltage (Vs), filter current (If), DC bus voltage (Vdc), reactive power (qs), active power (Ps) and PV power (Ppv) are depicted. The results show that the the network current become perfectly sinusoidal after the control application and remain in phase with the corresponding voltages. The change in radiation don't affect DC link voltage but change the line side active power and the amplitude of the line current. The reactive power is always zero.

We can observed from $[0.3 \mathrm{~s}-0.5 \mathrm{~s}]$ and $[0.8 \mathrm{~s}-1 \mathrm{~s}]$, the opposite phase between voltage and current source and the negative sign of the utility active power (Ps), meaning the filter current has information of harmonic and PV array currents to ensure elimination of harmonic and injection of current to the load. The dc link voltage returns to its reference value in few milliseconds, without overshoot and undershoots, as shown in Figure 12e, demonstrates the superiority of the PI-PSO controller compared to its counterpart PI controller.

Figure 13 show harmonic spectrum of source current at $0 \mathrm{~W} / \mathrm{m}^{2}$. The active filter decreases the total harmonic distortion (THD) from $27.57 \%$ to $1.83 \%$ with PI controller. However, with PI-PSO controller the THD is increased to $1.28 \%$ which proves the effectiveness of the proposed controller. Performance of proposed control is evaluated in term of THDi level behavior under fast changing irradiation as well as changing operation modes as shown in Table 5. 


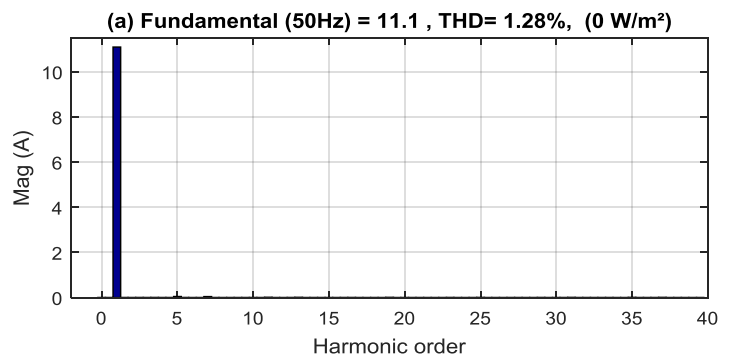

(a)

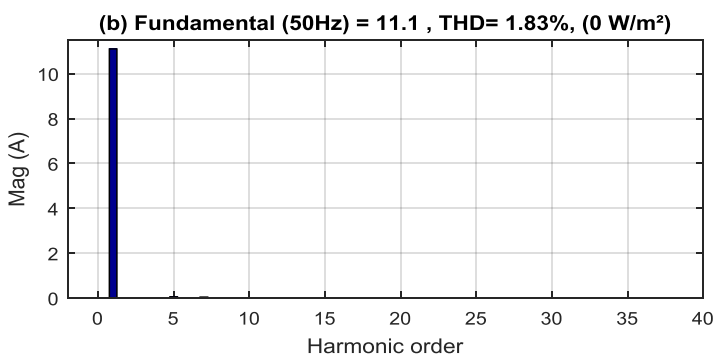

(b)

Figure 13. Harmonic Spectrum. (a) With PI-PSO Controller. (b) With PI Controller.

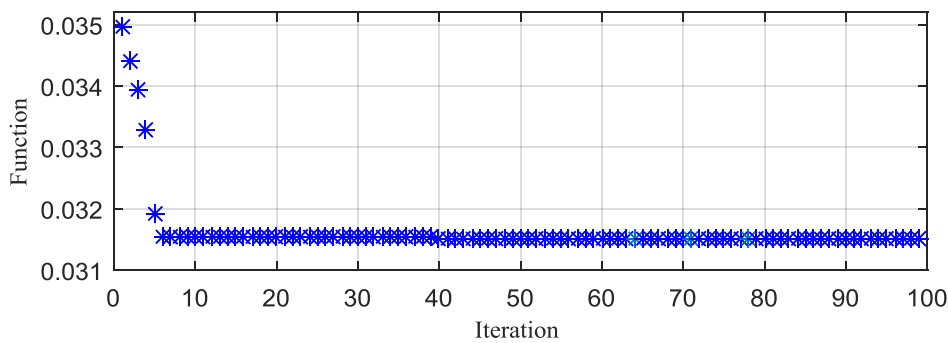

Figure 14. Error Function Evolution with Iterations for PSO Algorithm.

Table 5. Comparisons of DPC Indexes between Used and Unused PSO Algorithm

\begin{tabular}{ccccccc}
\hline & $k p$ & $k i$ & $\mathrm{THD}\left(0 \mathrm{~W} / \mathrm{m}^{2}\right)$ & $\mathrm{THD}\left(600 \mathrm{~W} / \mathrm{m}^{2}\right)$ & $\mathrm{THD}\left(200 \mathrm{~W} / \mathrm{m}^{2}\right)$ & $\mathrm{THD}\left(1000 \mathrm{~W} / \mathrm{m}^{2}\right)$ \\
\hline PI & 0.2 & 75.63 & $1.83 \%$ & $6.17 \%$ & $3.21 \%$ & $1.66 \%$ \\
PI-PSO & 0.365 & 23.547 & $1.28 \%$ & $4.25 \%$ & $2.18 \%$ & $1.16 \%$ \\
\hline
\end{tabular}

The simulation result shows that the improved particle swarm optimization PI control has a smaller overshoot during radiation change, low rise time and low source current THD compared to its counterpart PI controller. It can be concluded that the DPC with PI-PSO gives betters results for robustness, harmonic minimization and inject the maximum active power available from the PV array into the load and/or grid.

\section{CONCLUSION}

In this paper, a PSO based direct power control for a multifunctional grid connected photovoltaic system is investigated. the simulation results show a significant enhancement by applying the DPC with PIPSO controller in comparison with classical DPC in termes of response time, overshoot, THD and stability the systeme under irradiation changes. The optimization of the gains of PI controller for dc link voltage by using PSO algorithm presents a perfect efficiency to reduce the overshoot and undershoot of PI controller and gives better results for robustness and harmonic minimization.

\section{REFERENCES}

[1] V. Jyothi, T. Vijay Muni, S. Lalitha, "An Optimal Energy Management System for PV/Battery Standalone System," International Journal of Electrical and Computer Engineering, Vol. 6, No. 6, pp. 2538-2544, 2016.

[2] L. Hassaine, E. Olias, J. Quintero, A. Barrado, "Power control for grid connected applications based on the phase shifting of the inverter output voltage with respect to the grid voltage," Electric Power Systems Research, vol. 57, pp. 250-260, 2014.

[3] M. Haddad, S. Rahman, A. Hamadi, and K. Al-Haddad, "New Single Phase Multilevel Reduced Count Devices to Perform Active Power Filter," Proceedings of the IEEE SoutheastCon, pp. 1-6, 2015.

[4] P.N.Enjeti,W.Shireen, P.Packebush, J.Pitel d I, "Analysis and design of a new active power filter to cancel neutral current harmonics in three-phase four-wire electric distribution systems," IEEE Transaction on Industry Application, Vol. 30, pp. 1565-1572, 1994. 
[5] B.Boukezata, J.Gaubert, A. Chaoui, M. Hachemi," Predictive current control in multifunctional grid connected inverter interfaced by PV system," Solar Energy, Vol. 139, pp. 130-141, 2016.

[6] T.Noguchi, H.Tomiki, S.Kondo, I.Takahashi," Direct power control of PWM converter without power-source voltage sensors," IEEE Transaction on Industry Application. Vol. 34, pp. 473-479, 1998.

[7] A.Chaoui, J.Gaubert, and F.Karim,"Power quality improvement using DPC controlled three-phase shunt active filter," Electric Power Systems Research, Vol. 80, pp. 657-666, 2010.

[8] M.Bouzidi, S.Bouafia, A.Bouzidi, A.Benaissa, S.Barket," Application of Backstepping to the Virtual Flux Direct Power Control of Five-Level Three-Phase Shunt Active Power Filter," International Journal of Power Electronics and Drive System (IJPEDS), Vol. 4, No. 02, pp. 173-191, 2014.

[9] B.Berbaoui, C.Benachaiba, M.Rahli, H.Tedjini, "An efficient algorithm to tuning PI-controller parameters for shunt active power filter using ant colony optimization," PRZEGLADD ELEKTROTECHNICZNY (Electrical Review), Vol. 6, pp. 140-145, 2011.

[10] M. G. Villalva, J. R. Gazoli, E. R. Filho, "Comprehensive Approach to Modeling and Simulation of Photovoltaic Arrays", IEEE Transactions on Power Electronics, Vol. 24, pp.1198-1208, 2009.

[11] J.M. Enrique, J.M. Andu jar, M.A. Bohorquez, " A reliable, fast and low cost maximum power point tracker for photovoltaic applications, " Solar Energy, Vol. 84, pp.79-89, 2010.

[12] E.S.Sreeraj, K.Chatterjee and S. Bandyopadhyay,"One-Cycle- Controlled Single-Stage Single-Phase VoltageSensorless Grid-Connected PV System, "IEEE Transactions on Industrial Electronics, Vol.60, No.3, pp.12161224, 2013.

[13] K. Antoniewicz, M. Jasinski, M.Kazmierkowsk, M.Malinowski,"Model Predictive Control for 3-Level 4Leg Flying Capacitor Converter Operating as Shunt Active Power Filter," IEEE Transactions on Industrial Electronics, Vol. 63, pp. 5255 - 5262, 2016.

[14] M.S.Djebbar, H.Benalla," Performance and High Robustness DPC for PWM Rectifier under Unstable VDC Bus," International Journal of Power Electronics and Drive System (IJPEDS), Vol. 7, No. 1, pp. 66-74, 2016.

[15] J.Kennedy, R. C. Eberhart,"Particle swarm optimization," In Proceeding of IEEE International Conference on Neural Networks, pp.1942-1948, 1995.

[16] S. Saadi, M. Elaguab, A. Guessoum and M. Bettayeb,"Optimizing UPFC parameters via two swarm algorithms synergy," Proceedings of the 2012 IEEE systems, signals and devices (SSD), 2012 9th international multiconference, Chemnitz, pp. 20-23, 2012.

[17] L. Mazouz, S. Zidi, M. Khatir, T. Benmessaoud, S. Saadi, "Particle swarm optimization based PI controller of VSC-HVDC system connected to a wind farm," International Journal of System Assurance Engineering and Management. Vol 7. pp. 239-246, 2014. 